\title{
A Discussion of a Unique Collaboration Model Between Schools*
}

\author{
Werner de Klerk, Alida W. Nienaber \\ North-West University, Potchefstroom, South Africa
}

\begin{abstract}
The schools located in many township and rural areas of South Africa struggle to provide a high standard of education, because many of the inhabitants of these areas are very poor and there is, thus, a lack of the funding required for the necessary educational equipment. The Afri Twin project, started by Jayne Martin addresses this problem. The project is collaboration among a British school, a South African town/city school and a school from a rural community in South Africa. The aims of the research project were to determine the benefits of the Afri Twin project and to investigate a unique interaction among a British school, a South African Model C School and a rural school. Data were collected through focus group interviews, in-depth interviews and questionnaires. Data analysis led to the emergence of four major themes with categories and subcategories. The conclusion underlined the cultural tolerance that is established through the Afri Twin project as well as the importance of financial support for promoting an improved learning environment.
\end{abstract}

Keywords: Afri Twin, township, rural, schools, education

\section{Introduction}

According to Masitsa (2004), underachievement is a problem that no educational institution is immune to and that can affect any learner. Potential does not guarantee performance and a learner with the potential to perform well must still work hard to perform in accordance with that potential. Masitsa (2004) investigated four determinants of underachievement for learners in secondary schools in townships and found that these determinants have a definite influence on learners' performance. These determinants are the medium of instruction, a lack of textbooks, overcrowded classrooms and truancy. Research by Olivier (2006) also found that environmental factors, such as school set-up and domestic circumstances, have a great influence on a learner's motivation.

Donald, Lazarus, and Lokwana (2002) argued that poverty influences all aspects of teaching in schools. Despite of the promise of equal learning opportunities for all, many public schools in South African townships still have poor financial support (Ndimande, 2006). Financial contributions towards school funding are certainly the most important source of school financing. Because of social factors such as unemployment and poor parents, school management has to find other means to raise funds (Maarman, 2009; Du Plessis Venter,

\footnotetext{
* On August 5, 2008, an Afri Twin Conference was held in Cape Town. This was the first conference be held, and it gave participating schools the opportunity to share their experiences and to render advice. The second International Afri Twin conference was held on February 23, 2011.

Werner de Klerk, Research Psychologist, School for Psycho-social Behavioral Sciences, North-West University.

Alida W. Nienaber, Ph.D., Chair of Psychology, School for Psycho-social Behavioral Sciences, North-West University.
} 
1999). Bush and Hofstede (2003; as cited in Naidoo, 2005) pointed out that, even though township schools charge small amounts for school fees, they are still able to collect only 50\% of their potential school fees, because of the high levels of unemployment and the great number of parents who qualify for exemption from school fees. In South Africa, poverty is the single largest reason for children leaving school early (Minnaar, 2006). Poverty contributes to limited participation by parents in schools as well as underachievement of learners (Mbatha, 2005). Fund-raising for purchasing academic material and other necessities, such as clothing and food, Ngcobo (2005, p. 234) found, can have a positive influence on a school's academic performance.

According to Chisholm and Vally (1996; as cited in Mdletshe, 1999), the condition of school buildings and facilities has a significant influence on the climate of learning and teaching at a school. South African rural schools experience many challenges with regard to basic resources, such as water, sanitation and the safety of buildings (Mbatha, 2005). Poor infrastructure is common, with many schools having to cope with damaged school buildings, no bathrooms, no computers, no books and in some cases no facilities at all, where learners are taught under trees. The realities of life (life in general) on farms are not likely to change in the near future and it seems that schools have to play a more important role in supporting learners who live in dire poverty rather than pushing them out of the school community (Minnaar, 2006). A published report on rural education highlights the fact that rural education in South Africa "lags behind educational development in other parts of the country, despite the fact that the vast majority of school-going children in South Africa live in rural areas" (Nelson Mandela Trust, 2005, p. 132; as cited in Ngubane, 2005, p. 4).

According to the South African Institute of Race Relations (2008; as cited in de Wet \& Wolhuter, 2009), of the 25,415 public schools in South Africa, 4,046 have no electricity, 2,891 no source of water and 17,081 no computers. A mere $46 \%$ of grade one learners eventually reach Grade 12 (Rademeyer, 2008; as cited in de Wet \& Wolhuter, 2009). Further more, the South African Institute of Race Relations (2008; as cited in de Wet \& Wolhuter, 2009) also found that since 2003, the matriculation pass rate has been falling each year.

\section{Afri Twin Project}

A project that can possibly alleviate some of these problems is the Afri Twin project initiated by Jayne Martin (South African native) in the UK in 2001. Afri Twin works as follows: Schools of comparable type and size in Britain and South Africa are selected and then "twinned" with a third school in a rural or township area. At first, the schools became acquainted through the Internet or telephone. Learners and teachers then proceeded to study educational topics together. As the relationships among the different schools develop, opportunities will follow, allowing the schools to visit one another, exchange teaching ideas and experiences and gain first-hand experience of the different conditions in which the individual schools are operating. The emphasis is to have an equal interaction between the schools.

According to the website of Afri Twin, the goal of the project is to create an understanding of the challenges and achievements that are associated with the education system in less affluent communities (Afri Twin, sharing education together). Afri Twin is recognized as an innovative way through which to develop friendships, exchange knowledge, share different cultural aspects and experiences and encourage racial tolerance and good citizenship (Afri Twin, sharing education together). In 2008, 75 schools from the UK (primary and secondary schools), 75 well-resourced South African schools (primary and secondary schools) and 75 developing township and rural schools were already participating in the Afri Twin project.

The British Afri Twin schools pay 250 pounds per primary school and 350 pounds per secondary 
school per annum (BBC World Class). The Manchester, Cheshire, Lancashire and Plymouth Departments of Education are all aware of and supportive of their schools being involved in school linking with South Africa. Furthermore, the British Council (a large charity in the UK that provides finances for teachers to visit their twinned schools each way) has funded a great number of Afri Twin teachers to allow them to visit each other. According to Jayne Martin, the South African Department of Education is aware of Afri Twin, but is not as involved as it should be. The Western Cape Department of Education, however, is most supportive.

The British school, the South African Model C School and the South African rural school in this study are members of a specific group of schools in the Afri Twin project. The South African Model C School is a typical middle class school, with 1,004 learners, a staff of 28 permanent teachers and 17 governing body positions. Most of the learners come from middle-class homes and double medium instruction takes place (that is Afrikaans and English). The British school is an all-boys technical school with 950 boys between the ages of 11 and 16 in Manchester. They have a teaching staff of approximately 70, with an additional 15 members of support staff. The support staff is mainly made up of teaching assistants who help individual pupils with specific learning needs. In a 2007 Ofsted inspection by the Department of Education, the British School was judged as an outstanding school. The third school, the rural school, is situated in a rural area and is a very poor school with approximately 366 learners. They have a teaching staff of 12 and an additional two curriculum transformation positions (teachers provided by the Department of Education). School fees at the rural school were always 150 rand (ZAR (South African Rand)) per year, but at the beginning of April 2008, a letter from the Department of Education declared them a no-fee school.

The South African Model C School and the British School linked up with each other in 2005. Following a suggestion from Jayne Martin in 2006, a decision was made to establish a three-school link. This was followed by visits to a number of rural schools in the area and the rural school was identified as the school with the greatest need. The British school has the means to raise funds for the rural school, whilst the South African Model C School's location enables it to act as intermediary in the allocation of resources from the UK. Through fund-raising, they help in the development of the rural school.

The link between the South African Model C School and the British school has now expanded to incorporate the exchange of teaching staff as well. In 2007, a geography teacher exchange took place between the South African Model C School and the British school, whereby both teachers and their wives exchanged places for a five-week period. This included living in each other's houses, driving each other's cars, and doing each other's jobs. Every two years the Model C School will visit the British school for three weeks, living with their twins and attending school with them. The British school does the same every two years in between.

The question would, thus, be: How this unique collaboration model between schools influenced the learners and the schools involved?

\section{Objective}

This research project has the following objectives:

(1) To determine the benefits of the Afri Twin project for both the South African schools and the British school;

(2) To investigate the unique interaction between the learners and the schools involved. 


\section{Research Method}

A qualitative approach was found to be the most appropriate to elicit information from the participants, as it is difficult to investigate attitudes and feelings quantitatively (Walker, 1999). Qualitative researchers collect data in the form of written or spoken language and analyze the data by identifying and categorizing themes based on the research method followed by Durrheim (2006).

\section{Research Design}

The research design for this research project is a case study approach. Merriam (1998, p. 27) described the qualitative case study method as "an intensive, holistic description and analysis of a single instance, phenomenon, or social unit”. The most important reason for employing case studies, however, is that a case study's emphasis is on an individual unit, group or an organization. A case study is used in order for the researcher to acquire a better understanding of the meanings attached by those within the system. In this case, the three schools involved in the Afri Twin project were used for the case study.

\section{Participants}

All the participants shared commonality in that they all were or are involved in the Afri Twin project. In qualitative research, the number of participants is not important, but rather their experiences and expected views (Creswell, 2005). The three schools involved in this research study were selected on the basis of availability. The following individuals participated in the Afri Twin project:

(1) South African Model C school: Six girls between the ages of 13 and 17, the principal (male), the teacher (female) who is the organizer of the project at the school, the deputy principal (male) who went to the British school for five weeks in the exchange of teaching staff and one parent;

(2) British school: Seven boys between the ages of 13 and 16, two teachers (male and female) who are involved in the organisation of the project at the school, and the teacher and his wife who visited the two South African schools for five weeks during 2007;

(3) South African rural school: Three boys and five girls between the ages of 15 and 18, the principal (male), the teacher (female) who assists in the library and teaches geography, and the teacher (female) who assists with the computer centre and reading room for the school and who also teaches physical science and life science at the school.

\section{Data Collection}

To collect the data, in-depth interviews and focus group interviews were held and a questionnaire was drawn up from discussions with Jayne Martin. According to Babbie, Mouton, Voster, and Prozesky (2001), in interviews, most of the talking is done by the respondent, because he/she is the provider of information. The informal group discussion atmosphere of the focus group interview structure is intended to encourage subjects to speak freely and completely about behaviors, attitudes and opinions they possess (Berg, 1995). In any qualitative research project, a questionnaire forms the means by which a researcher can obtain information, regardless of the technique applied. Therefore, questionnaires cannot be seen in isolation (Dlamini, 2006).

\section{Data Analysis}

Data collected in the process of this research project were transcribed into text and presented in a narrative form. According to Terre Blanche, Durrheim, and Kelly (2006), data analysis involves reading data repeatedly, engaging in activities of breaking the data down (thematising and categorising) and building it up again in 
novel ways (elaborating and interpreting). Themes were identified and coded during the theme development process. This entailed marking different sections of the data as being instances of or relevant to, one or more of the themes (Terre Blanche et al., 2006).

\section{Issues of Trustworthiness}

In qualitative research, trustworthiness is an indication of "methodological soundness and adequacy" (Holloway \& Wheeler, 2002, p. 254). Trustworthiness for this research was accomplished by means of prolonged engagement with the participants, comparing the raw data and findings, peer examination, consultation with the participants (member checking) and triangulation (using multiple methods for gathering information). According to De Vos (2002), triangulation not only allows the researcher to take multiple measures of the same phenomenon, but also to establish confidence in the research results.

\section{Ethical Measures}

Ethical approval was obtained from the Ethics Committee of the North-West University (Potchefstroom Campus: NWU-0072-08-S1). The essential purpose of research ethics is to protect the welfare of research participants (Wassenaar, 2006). Therefore, ethical considerations were taken into account by respecting the rights, needs, values and desires of the participants (Creswell, 1994). Consent was obtained from the three schools. The different parties (the three headmasters and teachers) were requested to sign consent forms as well as the parents of the learners that participated were requested to sign the consent forms. Informed and voluntary participation was ensured in this way. The participants were informed that their identity would be protected and that they could withdraw from the research project at any time.

\section{Research Findings}

Four major themes emerged from the analysis of the data collected. Each theme was differentiated in terms of various categories and subcategories. Appropriate verbatim quotations from the transcribed interviews were provided as validation. Some of the participants did not have a very good command of the English language, as it was evident in some of the quotations.

\section{Theme 1: The Collaboration Between the British School, the South African Model C School and the South African Rural School}

The link between the British school and the South African Model C School. Every two years the British school and the South African Model C School select a new group of learners (12 in a group) to be a part of the Afri Twin project. The learners then make contact with their twin through e-mail to build up a friendship. One year, the South African Model C School will visit the British school for three weeks with a teacher, and the next year, the British school will come to South Africa to visit the two South African schools. The learners selected at South African Model C School are usually from Grades 8 and 9, and the learners at British school are aged between 13 and 16. The learners from both schools have to carry all the costs involved for the trip themselves. The learners usually do all kinds of fund-raising throughout the year to help with the costs as these learners comment: (1) We do all kinds of fundraising to help us with the costs; and (2) We usually sell things at the tuck shop to help with fundrasing.

The link with the South African rural school. The main objective of the South African Model C School and British school is to aid the rural school in developing and improving their school as this teacher comments: 
enables them to act as intermediary in the allocation of resources from the UK. We have raised a significant amount of money to aid in the development of the rural school and to improve the school.

Each year, needs are determined by the principal and teaching staff of the rural school and problems at the school are then prioritized and placed in a "wish list". The list is handed over to the South African Model C School, who in turn investigates every item in the list. This is partly to determine whether the wishes fall within the South African educational context. If so, they then help rural school to meet their needs by using funds raised by British school.

Form of fund-raising to help the rural school. A common form of fund-raising at the British school is bag-packing at supermarket pay points, where learners pack shoppers' goods and receive tips. Several hours of packing usually raise hundreds of pounds. Another fund-raising method is a "mufti" day, on which learners pay a small amount of money to wear clothing of their choice for a day, rather than the normal school uniform. At the summer and autumn fairs of the school, funds were boosted from a stall selling goods. Wares sold included some artefacts brought from South Africa by the Afri Twins in 2007. In 2008, a neighboring church gave a generous donation to the school to aid the South African rural school. During the donation ceremony, a presentation took place which informed the congregation about the plight of the learners of the rural school. A teacher from the South African Model C School with the well-known Northern KwaZulu-Natal Youth Choir, of which he was the conductor, also visited England in 2007 and 2008. During the visit, a number of performances were undertaken to raise money for Afri Twin where the British school provided the venue and sold the tickets.

The teacher exchange between South African Model C School and the British school. As previously mentioned, both teachers from the South African Model C School and the British school traded places for five weeks during 2007. The South African Model C School teacher had four areas which he wanted to investigate: (1) how outcome-based education works in Britain; (2) the use of modern technology in the class environment; (3) the importance of the media centre and research methods in a first-world country; and (4) the discipline system being applied in the school.

During his exchange, the South African Model C School teacher was asked to give a non-examination subject at the British school and tell students about South Africa. Specific reference was made to the Apartheid years, affirmative action, and the basic way of life in South Africa covering birth to married life and also the different cultural groups residing in South Africa.

The British school teacher, accompanied by his wife, came to teach at the South African Model C School and his wife became involved at the rural school, finalizing the library and establishing the reading room. At the South African Model C School, geography lessons were given, but no managerial duties were performed. Learners were able to ask questions about the differences between the schools. To quote the British school teacher:

Despite both teachers from the South African Model C School and I being senior managerial staff at our respective schools, we did not swop any managerial duties. We did, however, both run whole school assemblies during which we were able to describe our home schools. The pupils (learners) were able to ask any questions about the differences between the schools. One of the beauties of the exchange was the inevitable interest and questions generated by learners in informal settings of the playground between lessons and at the end of formal lessons.

He also went on to add the following very important comment:

On returning to England, my wife and I have spoken at many events about our exchange. We created several power 
point presentations of the exchange and have used them at school, at church coffee mornings and with colleagues. These have been a valuable tool, enabling people to understand the similarities and the differences between the three schools. In conclusion, I think the exchange was a success in bringing all three schools nearer together. The pupil exchange system of the Afri Twin project is a success and should continue in its present state to unite the three schools. Further staff exchange should be encouraged, but I would suggest that a timetable commitment should be made in both South African schools for any member of staff going to South Africa in future. My regret was that I was unable to devote more teaching time to the South African rural school.

\section{Theme 2: Advantages for the British School, the South African Model C School and the South African Rural School}

With this unique interaction among the three schools, the following advantages were mentioned and identified.

The British school. According to the British school, the main advantage of the Afri Twin project is the unique experience it gives to their learners. The learners not only have the chance to travel to South Africa, but also to have a truly South African experience by visiting different places, such as Sun City, having a truly wild life experience by visiting the Pilanesberg Game Park and also going to Cape Town. Some of the favorite parts for the learners are living with their host families, visiting the local townships and going to a traditional Zulu village.

According to the British school, the Afri Twin project also informs their learners, who are not directly involved, of the wider world and issues that exist in another country. This is illustrated in one of the teacher's comments:

There are various assemblies held where information about the two South African schools is updated, making all students aware of what we do, particularly relating to raising money for the rural school and the changes it brings about.

As illustrated by this learner's comments, the learners who visit the two South African schools also learn to appreciate what they have:

I think that the people that come here they learn to appreciate what we have; you don't really have ... you take it for granted. You come over here and see that they do not have what we have, like we have free education and free health service and things like that. It just helps you to appreciate and not take everything for granted.

Afri Twin is also used to support the curriculum at this British school as this teacher comments:

To date, Afri twin is used in geography, history, music, drama, religious education, science, English, travel and tourism and business studies. In British schools, there is presently as massive drive to increase the global awareness of all school children. Our school was well ahead of this, as the global dimension was already in use, expanding the awareness our students have of the world beyond their immediate communities. It also served to dispel negative preconceived stereotypical viewpoint of Africa and African people.

The South African Model C School. The response of South African Model C School corresponds with that of British school, stating that the biggest advantage for the Afri Twin learners is to go overseas with two teachers for three weeks for a third of the normal cost. They also get a chance to experience the English life style by living with their Afri Twin partners, going to school with them and enjoying the British scenery.

The South African Model C School emphasizes that their Afri Twin learners learnt to be self-confident, to develop emotional stability, to handle difficult situations and as a result, become more mature, because of their participation in the project. Here is one of the comments from a teacher: 
One of the parents told me that she had doubts about the possible security risks to her daughter, but sent her on the tour anyway. On their return, she could not believe the difference three weeks had made. A confident, more stable and mature child returned.

According to the South African Model C School, they also get a chance to learn from each other's cultures and discover exactly how a rural school learner's life really is. They also appreciate what they have if they look at the life of the underprivileged children at the rural school. According to the interviewees, it is also a great way to make friends.

The South African rural school. Because of financial support, the project has a great influence on the South African rural school. With the help from the British school and the South African Model C School, the South African rural school built a library room, reading room, computer class and a science laboratory for life sciences and physical sciences. Each of these is considered separately as follow:

Library room. The wife of a British teacher, who exchanged places for five weeks, came to the rural school and helped them to organize the library room and label all the books. Both the British school and the South African Model C School sponsored books and the South African Model C School helped to cover the books. The South African rural school is very grateful for the library room as illustrated by the teacher who assists with the library:

You know, two years ago we did not have a library at the school at all, we had some books from the Department of Education, but there were no library. Now that we have a library, it is an eye opener for the learners, they get a chance to come in here and do their assignments and everything, even the teachers now have a lot of references for preparing their lessons. So, it is a very good thing, learners are taking books and reading and it is helping with their English. So, the library is a very good experience for the school.

According to one of the teachers, English levels at the school are very poor and they hope that the books will help develop their English language skills. The principal and their Afri Twin learners are very grateful for the library room.

Reading room. In addition to helping paint the inside of the room, the South African Model C School also sponsored some pillows to sit on and donated magazine racks. The teacher at the rural school, who kept an eye over the reading room, also gave chairs for the reading room. The children may go to the reading room whenever they wish (aside from class hours) to read books and magazines.

Computer room. With the financial support of the British school, the South African Model C School could help the rural school by giving them a computer class with Internet. Computers have become an integral part of daily life. Schools prepare children for productive lives in society. The "real world" has embraced computer applications wholeheartedly. Therefore, learners need to learn to use those tools in school (Lockard \& Abrams, 2001). The South African Model C School installed a new ceiling, fitted new floor tiles, fitted burglar bars to all the windows and the door, undertook restoration work on desks, decorated the room, donated 16 computers, computer software and two printers and set-up access to the Internet.

The Department of Education provided the rural school with two curriculum transformation positions, of which one is for computer studies (ITC (information and communication technologies)) and mathematics and the other is for physical science. Learners need "teachers who could show them how to use computers as productivity tools” (Johnson \& Bartleson, 2001, p. 41). One of the comments is as follows:

Those who are using the computers, it is a eye opener for them, it is something that they never have seen before, it is something that they just touch a button and gets information so for them and it is very good. For us as teachers, because we 
are computer illiterate, we get a chance to do some things on the computer. There is a programme for the teachers attending after school for six weeks to make them computer literate.

There are already two computer literate teachers, because of the computer classes and they now assist learners and other teachers with the computers.

Science laboratory. This was the latest project, which was completed at the end of September 2008. The South African Model C School painted the inside of one of the rooms at the rural school, furnished it and obtained some chemicals for physical science, as well as a cubicle at the back of the class where there is a washbasin and storage cupboards for all the apparatus.

Some of the other advantages for the rural school are that the South African Model C School sometimes come with soccer and netball teams and play against the rural school. When the British school visits, the boys also have a game of soccer with the rural school. The rural school gets a chance to hear about the English life and interact with learners from overseas. Afri Twin gives the learners of the rural school more confidence because they feel that they are now getting the same things that schools in town have to offer. When British school comes to visit, they also give the rural school donations, such as soccer jerseys.

\section{Theme 3: Cultural Interaction}

The learners and teachers interacting with each other have different life styles and learn much from each other. The absolute difference between city life and a poor rural environment is experienced first-hand. The more affluent learners gain a lot of respect for the learners from the rural school who walk kilometers to school in all kinds of weather and they have a hunger to learn despite of so many obstacles. A British school teacher stresses:

The cultural experience gained in South Africa undoubtedly has an impact on the learners. They are all aware of the different life styles led throughout the country. To enhance this, our Afri Twins visit the townships of Osisweni and Madadeni and later go to a Zulu village where they are given traditional greetings and meet different members of the community.

The language of the learners seems to be an obstacle to communication between the South African Model C School and the rural school. The rural Zulu learners are more reserved and take longer to connect, but the Zulu children remain keen to learn from the South African Model C School and British school learners and help wherever possible with projects to uplift their school. For the rural school, it is an absolute novelty to connect with learners from another country. When the British school comes to visit, the rural school asks things, such as what the weather is like and how people in England live. They also like to make comparisons as this teacher from the rural school comments:

For our kids, it is a good thing because they have never been exposed to overseas learners, let alone white learners. So to connect with them and what they have done and have them enlighten us about life outside South Africa. We also ask them a lot of questions, they tell us about things like the weather and everything. So it is very good for the school.

\section{Theme 4: Problems}

Both the Model C School and rural school wish to establish the rural school as a community centre. This will enable members of the community to have free access to the library and computer room. The library is already available for the community, and the aim is to have adult computer classes. However, this cannot be done, as a tutor is not available after hours. This is emphasized by the headmaster of the rural school: 
The library and computers are not just for the learners and the community also has access. They can come and borrow books and all that. At parent meetings, we also sell them the importance of Internet and that they can use it. The only shortcoming is the only time we can have the community is after school hours and then there are no teacher, the teacher has left... The only time they have is during weekends, so if we have enough money, perhaps we could get someone to do that.

The daily schedule does not allow any time for computer lessons. This means special time has to be set aside for learners to attend computer lessons. One way is to take one class randomly at a time when "extra mural” activities are scheduled. The added problem of only having 16 computers and no timetable for computer classes results in some learners not being able to work on the computers at all. As this teacher comments:

There are some concerns about the computers; because there are only 16 computers and we have a lot of learners. We cannot teach all of the learners, and unfortunately, some learners leave before they get to experience the computer centre.

However, according to the principal, the teacher that the department provided does try to group all the learners in the school accordingly when it comes to the computers.

Because the computer room only has 16 computers, whilst the size of classes is on average between 27 and 56 learners, the school has to group between three and six learners per computer simultaneously. This is not ideal at all. Each learner works for a few minutes and then has to vacate the seat for the next one in the little group. At the end of the session, each learner is assessed individually.

Some other problems are that the tables for the computers are too low and there is not enough space on the tables for everything to work comfortably, so, it sometimes happens that learners have to work with the keyboards perched on their laps. Despite of these obstacles, the school has a wonderful attitude and is very grateful for the computer room. To quote the principal: "I always tell everyone it is better to have half a loaf of bread than no bread at all”.

The long-term goal of the Model C School and British school is to give the rural school the opportunity to go on an overseas trip as well, for the whole idea of Afri Twin is that all the schools get to be on an equal level. Understandably, finances are currently the largest obstacle to this, according to Jayne Martin, a teacher from the rural school went to visit the British school for three weeks during 2010.

As the learners have to pay for themselves, one of the problems regarding the exchange between the British school and the South African Model C School is the cost of visiting each country. There have also been occasions where the learners are not happy with their twins or do not keep in touch with their twin throughout the year. As this teacher comments:

The main disadvantage of the scheme is the cost of visiting each country as we are so far apart. While we can identify individuals that could benefit a great deal from the scheme, they are unable to take part if they cannot afford it, and there is no budget to help them financially in such circumstances. Personality clashes have occurred between Afri Twins whilst on the host visits. Tact and diplomacy had to be used to rematch and re-home Afri Twins with similar personalities to themselves. On one occasion, the situation was remedied by Afri Twins re-matching themselves with other partners before the situation came to a head. The fact the trips can only occur on a biennial basis, though not a major disadvantage is a drawback of the arrangement. In a typical cycle, students are paired with their Afri Twin for up to a year before they first meet. This gives them misconception that the meeting is a distant event, and as a result, the Afri Twins are initially slow in making and maintaining contact. As the date draws closer, the students panic and make contact frequently, as they should have done from the start.

\section{Conclusions}

The objectives of the research project were to determine the benefits of the Afri twin project, investigate 
the unique interaction between three schools and determine the cultural enrichment of the learners and the multi-cultural interaction between the three schools.

According to Jayne Martin, the benefits of the Afri Twin project for the schools involved are the learning opportunities to find out more about the UK and South Africa, discover similarities and differences and develop realistic perceptions because of this knowledge. Some other benefits include: the forging of friendships; the building of international links; improvement of communication skills; two-way knowledge transfer; the opportunity to learn alternative skills and values; pride, self-esteem and personal growth for all participants; and most of all to acquire racial tolerance (Afri Twin, sharing education together).

The research project found that there is a unique interaction between the three schools, with the British school and the South African Model C School who visit one another (including the teacher exchange), helping to aid the South African rural school in developing and improving their school.

The influence of the financial support is evident in all three schools. As benefactor, the British learners involve the rest of their school and community in fund-raising projects. A culture of "giving" is cultivated. As financial intermediary, the South African Model C school learners get to see first-hand the difference between town and rural schools and the impact finances has on their education. As beneficiary, the rural school gains a tremendous amount. Literature tends to ignore the fact that good teaching does not just happen and teachers need support (Ngobeni, 2005). The rural school was helped to establish a functional library, a reading room, a computer room and also a science laboratory. The academic atmosphere at the school is changing, and in turn, this is helping to promote a sense of academic achievement.

The cultural influence is instant, as all learners and teachers stated in their interviews, it changed the way they look at other culture groups dramatically. The learners stated that they enjoy learning from each other's way of life and that the Afri Twin project is truly a cultural revelation. Children who live in poverty are not surrounded by a stimulating middle-class environment and may have little chance to develop self-esteem and many basic skills considered natural to children of a more advantaged background (A. E. Ivey, M. B. Ivey, \& Simek-Morgan, 1993). With the Afri Twin project, the rural school learners can develop their self-esteem further because they all feel that they now have opportunities equal to those schools in town because of the library, computers and laboratory.

The research question "How this unique collaboration model between schools influenced the learners and the schools involved?" can be answered as follows: The influence is measurable in monetary terms with the structural and equipment acquisition, but immeasurable on cultural level. Young minds are being changed to view each other and the world differently, tolerate difference and care. At a national level, the Afri Twin project is bringing change to the schools involved. It is slowly but surely raising the academic standard of the disadvantaged in South Africa and building cultural bridges.

Van der Westhuizen (2002) stated that a school with a healthy organizational structure which is not subject to undue pressure from the community has a principal who gives dynamic guidance, a teaching staff who are dedicated and learners who are motivated and who have goals that are attainable, as well as sufficient resources. It is clear that the Afri Twin project can help in this regard.

Because this is a case study, the research findings cannot be generalized in their comparison to any other schools also participating in the Afri Twin project. This collaboration is unique to these three schools.

In order to gain a better understanding of the long-term effects and benefits of the Afri Twin project, especially from the part of the learners, it is recommended that more in-depth research be done on more of the 
schools involved. Results can then be compared, and the impact can be measured. At a practical level, the project has shown to be effective, and it is thus recommended that more schools get involved in the Afri Twin project.

\section{References}

Afri Twin. Sharing Education Together. (n.d.). Retrieved November 14, 2007, \& January 20, 2010, from http://www.afritwin.net/

Babbie, E., Mouton, J., Voster, P., \& Prozesky, B. (2001). The practice of business and social research. Oxford: Oxford University Press.

BBC World Class. Get started-Afri Twin. (n. d.). Retrieved November 14, 2007, from http://www.bbc. co.uk/worldclass/getstarted _ afritwin.shtml

Berg, B. L. (1995). Qualitative research methods for the social sciences (2nd ed.) Needham Heights, M. A.: Allyn \& Bacon.

Creswell, J. W. (1994). Research design: Qualitative and quantitative approaches. Thousand Oaks, California: Sage Publications, Inc..

Creswell, J. W. (2005). Education research (2nd ed.). New Jersey: Pearson Education, Inc..

De Vos, A. S. (2002). Research at grass roots for the social sciences and human service professions (2nd ed.). Pretoria: Van Schaik.

De Wet, C., \& Wolhuter, C. (2009). A transitiological study of some South African educational issues. South African Journal of Education, 29, 359-376.

Dlamini, V. S. (2006). Effective parental involvement in township schools (Doctoral Dissertation, University of Zululand).

Donald, D., Lazarus, S., \& Lolwana, P. (2002). Educational psychology in social context (2nd ed.). Cape Town: Oxford University Press.

Du Plessis Venter, G. (1999). Guidelines for effective classroom control in township school (Master’s Thesis, University of Johannesburg).

Durrheim, K. (2006). Research design. In Terre Blanche, Durrheim, \& Painter (Eds.), Research in practice: Applied methods for the social sciences (2nd ed., pp. 33-54). Cape Town: UCT Press.

Holloway, I., \& Wheeler, S. (2002). Qualitative research in nursing. Oxford: Blackwell.

Ivey, A. E., Ivey, M. B., \& Simek-Morgan, L. (1993). Counseling and psychotherapy: A multicultural perspective (3rd ed.). Needham Heights, M. A.: Allyn and Bacon.

Johnson, D., \& Bartleson, E. (2001). Assessing technology skills for educational leaders. Learning and Leading with Technology, 29(2).

Keeves, J. P., \& Lakomski, P. (Eds.) (1999). Issues in educational research. New York: Elsevier.

Lockard, J., \& Abrams, P. D. (Eds.) (2001). Computers for the 21st century educators (5th ed.). New York: Longman.

Maarman, R. (2009). Manifestations of "capabilities poverty” with learners attending informal settlement schools. South African Journal of Education, 29, 317-331.

Masitsa, M. G. (2004). Four critical causes of underachievement in township secondary schools. Acta Academica, 36(1), 213-245.

Mbatha, P. N. (2005). The implementation of an institutional support team in a rural primary school in KwaZulu-Natal (Master's Thesis, University of Johannesburg).

Mdletshe, K. D. (1999). Characteristics of an effective township school for quality assurance (Doctoral Dissertation, Rand Afrikaans University).

Merriam, S. B. (Ed.) (1998). Qualitative research and case study applications in education. San Francisco, C. A.: Jossy-Bass.

Minnaar, L. (2006). Causes of school dropout among learners in a rural farm school (Master's Thesis, University of Zululand).

Naidoo, G. (2005). Budget monitoring and control as an aspect of financial management in township schools on the West Rand of Gauteng (Master's Thesis, University of Johannesburg).

Ndimande, B. (2006). Parental "choice”: The liberty principle in education finance. Perspectives in Education, 24(2), 143-156.

Ngcobo, T. M. (2005). The relationship between academic performances, school culture and school leadership in historically disadvantaged African township secondary schools: Implications for leadership (Doctoral Dissertation, University of KwaZulu-Natal).

Ngobeni, T. S. (2005). The implementation of outcomes-based education in rural primary schools: A management perspective (Master's Thesis, University of Limpopo).

Ngubane, W. S. (2005). An investigation into implementation of participative management in a rural school in the Pietermaritzburg district (Master's Thesis, Rhodes University).

Olivier, M. A. J. (2006). The impact of deprived environments on learner motivation. Africa Education Review, 3(1+2), 48-66.

Terre Blanche, M., Durrheim, K., \& Kelly, K. (2006). First steps in qualitative research. In Terre Blanche, Durrheim, \& Painter (Eds.), Research in practice: Applied methods for the social sciences (2nd ed., pp. 320-344). Cape Town: UCT Press.

Van der Westhuizen, P. C. (2002). Schools as organizations. Pretoria: Van Schaik Publishers.

Walker, H. J. (1999). Clarifying the affective component of psychological well-being (Master’s Thesis, North-West University).

Wassenaar, D. R. (2006). Ethical issues in social science research. In M. Terre Blanche, K. Durrheim, \& D. Painter (Eds.), Research in practice: Applied methods for the social sciences (2nd ed., pp. 60-79). Cape Town: UCT Press. 